\title{
Pengelolaan Kelas Pada Pembelajaran Tematik Terpadu Kelas V Sekolah Dasar
}

\author{
RTS Salma ${ }^{1}$ \\ ${ }^{1}$ SDN 122/IX Petaling, Jambi, Indonesia
}

\begin{tabular}{l} 
Article Info \\
\hline Article history: \\
Received Mei 9, 2020 \\
Revised Mei 16, 2020 \\
Accepted Mei 28, 2020 \\
\hline
\end{tabular}

\section{Keywords:}

Pengelolaan Kelas

Sekolah Dasar

Tematik

\begin{abstract}
ABSTRAK
Tujuan Penelitian: Berdasarkan hasil observasi di SDN 122/IX Petaling, Penelitian ini bertujuan untuk mendeskripsikan pengelolaan kelas pada pembelajaran tematik terpadu kelas V Sekolah Dasar.
\end{abstract}

Metodologi: Data penelitian diperoleh dengan menggunakan pendekatan kualitatif dengan jenis penelitian deskriptif. Dengan menggunakan penelitian deskriptif yang diperoleh dari hasil observasi dan didukung dengan hasil wawancara serta dokumentasi. Setelah data didapatkan maka data kualitatif dianalisis dengan menggunakan teknik analisi Miles dan Huberman.

Temuan Utama: Hasil penelitian menunjukkan bahwa guru dalam mengelola pengelolaan kelas pada pembelajaran tematik terpadu kelas $\mathrm{V}$ Sekolah Dasar Negeri 122/IX Petaling telah melakukan dengan baik. Hal ini terlihat berdasarkan hasil observasi dan didukung dengan hasil wawancara dan dokumentasi yang dilakukan oleh peneliti kepada guru kelas $\mathrm{V}$ dengan berpodaman pada indikator yang digunakan pada penelitian.

Aplikasi dalam Penelitian: Kemampuan dalam pengelolaan kelas sangat penting dimiliki oleh guru agar terwujudnya tujuan dari sebuah pembelajaran.

Keterbarauan: Dengan memiliki kemampuan pengelolaan kelas yang baik, maka siswa akan nyaman dan mendapatkan apa tujuan sebenarnya dari pembelajaran yang dilakukan.

Copyright $\odot 2020$ Cahaya Ilmu Cendekia Publisher. All rights reserved.

Corresponding Author:

RTS Salma

SDN 122/IX Petaling, Jambi, Indonesia

Email: rtssalma122@gmail.co.id

\section{PENDAHULUAN}

Kurikulum yang sedang dipakai secara nasional pada saat ini adalah kurikulum 2013. Pada kurikulum 2013 pembelajaran dilakukan menggunakan tematik terpadu. Pembelajaran tematik terpadu merupakan pembelajaran yang dibuat dalam bentuk tema berdasarkan muatan mata pelajaran yang dipadukan. Tema digunakan sebagai pemersatu, didalam tema terdapat semua mata pelajaran kecuali mata pelajaran Matematika, Agama dan Pendidikan Jasmani dan Kesehatan yang dipisahkan dan berdiri sendiri. Sehingga pada saat pelaksanaan pembelajaran beberapa mata pelajaran yang telah ditentukan dipadukan menjadi satu didalam sebuah tema. [1] pembelajaran tematik terpadu merupakan suatu kegiatan yang dilakukan dalam menyatukan pemikiran, nilai dan sikap, keterampilan serta kemampuan dalam menggunakan tema yang akan dipergunakan. Pembelajaran tematik terpadu pengelolaan kelas sangat diperlukan, ruangan kelas ditata sesuai dengan tema, suasana pada saat pembelajaran dibuat menyenangkan, posisi tempat duduk siswa dapat diatur dan dipindah posisikan serta pembelajaran tidak selalu dilakukan dalam kelas tetapi bisa juga dilakukan diluar kelas [2]. Pengelolaan kelas pada pembelajaran tematik terpadu sangat diperlukan untuk dilaksanakan pada pembelajaran dikelas. 
Pembelajaran tematik terpadu adalah pembelajaran yang menggunakan tema sebagai pemersatu [3]. Proses pembelajaran tematik terpadu akan terlaksana dan tercapai dengan baik apabila pengelolaan kelas pada pembelajaran berjalan dengan baik. Pengelolaan kelas yang baik di dalamnya meliputi berbagai komponen-komponen keterampilan dasar yang harus dikuasai dan dipahami oleh seorang guru dalam melaksanakan proses pembelajaran [4]. Dengan kondisi kelas yang dikelola dengan baik akan mempengaruhi proses pembelajaran dan hasil pembelajaran, sehingga sangat penting untuk dilakukan pengelolaan kelas pada pembelajaran yang dilakukan oleh guru [5].

Berdasarkan hasil observasi yang dilakukan selama kegiatan pengenalan lapangan persekolahan di Sekolah Dasar Negeri 122/IX Petaling. Terlihat bahwa pada saat kegiatan proses pembelajaran di kelas guru sudah melaksanakan pembelajaran dengan baik, itu terlihat pada pengelolaan kelas yang dilakukan oleh guru pada pembelajaran. Sebelum kegiatan awal pembelajaran di mulai, guru mengatur posisi tempat duduk siswa, sehingga siswa akan berpindah dan berada di tempat duduk dengan teman yang berbeda. Pada kegiatan awal pembelajaran dimulai dengan berdo'a bersama, begitu juga pada saat jam terakhir pembelajaran. Selanjutnya pada kegiatan pendahuluan pembelajaran guru melakukan apersepsi dengan membahas materi pembelajaran yang sebelumnya, baru masuk kepada materi yang akan di pelajari. Pada kegiatan pembelajaran yang dilakukan guru lebih banyak menggunakan berbagai metode yang bervariasi sehingga siswa memperhatikan guru dan proses pembelajaran serta kondisi kelas terkendali [6]. Selain itu berbagai kelengkapan atau perangkat pembelajaran juga sudah tersedia dengan baik [7]. Pengelolaan kelas yang baik akan mempengaruhi pencapaian hasil pembelajaran, sehingga pengelolaan kelas pada pembelajaran tematik terpadu perlu di ketahui, untuk mengetahui hal tersebut peneliti perlu melakukan penelitian.

\section{METODE PENELITIAN}

Penelitian ini menggunakan pendekatan penelitian kualitatif yang akan menghasilkan data deskriptif dengan berusaha mengungkapkan pengelolaan kelas pada pembelajaran tematik terpadu kelas V Sekolah Dasar Negeri 122/IX Petaling

Teknik analisis data yang digunakan dalam penelitian ini yaitu berupa analisis deskriftif kualitatif. Data yang diperoleh dari lapangan melalui observasi, wawancara, dan dokumentasi, selanjutnya akan dilakukan analisi data [8]. Aktivitas dalam analisis data kualitatif dilakukan secara interaktif dan berlangsung secara terus-menerus sampai tuntas, sahingga datanya sudah jenuh. Aktivitas dalam analisis data, yaitu mengumpulkan data, reduksi data, penyajian data dan kesimpulan. Teknik pengumpulan data yang digunakan dalam penelitian ini adalah teknik observasi, wawancara dan dokumentasi.

Serta analisis yang digunakan menggunakan rancangan Miles \& Huberman. Yang meliputi mereduksi data, menampilkan data, dan menyimpulkan [9].

\section{HASIL DAN PEMBAHASAN}

Berdasarkan hasil penelitian, maka dapat dijelaskan sebagai berikut:

1) Keterampilan membuka dan menutup pembelajaran

Pada kegiatan membuka pembelajaran dilakukan dengan mengucap salam terlebih dahulu dan kemudian dilanjutkan dengan do'a yang dilakukan secara bersama, selanjutnya melakukan sebuah permainan. Permaianan dilakukan bertujuan untuk membangkitkan minat belajar dan konsentrasi siswa. Selain itu guru juga melakukan apersepsi dengan membahas kembali materi pembelajaran sebelumnya yang telah dipelajari baru masuk kepada materi pembelajaran yang akan di ajarkan.

Pada kegiatan menutup pembelajaran dilakukan dengan bertanya kepada siswa mengenai materi yang baru dipelajari, selanjutnya baru guru memberikan kesimpulan terhadap pembelajaran. Dalam memberikan kesimpulan, guru terlebih dahulu menanyakan kepada siswa mengenai pembelajaran yang telah dipelajari, baru dilanjutkan dengan penjelasan sekaligus kesimpulan terhadap pembelajaran yang telah dilakukan. Dalam mengevaluasi pembelajaran dilakukan dengan lisan dan tulisan, evaluasi lisan terjadi pada saat proses pembelajaran terjadi sedangkan evaluasi tertulis dilakukan tes pada akhir tema untuk mengukur kemampuan siswa dan ketercapaian pembelajaran yang dilakukan [10].

\section{2). Keterampilan menjelaskan pembelajaran}

Guru kelas V menjelaskan materi pembelajaran sesuai dengan contoh yang ada di buku, selanjutnya baru ditanyakan kepada siswa contoh lain yang ada dilingkungan sekitar dan diperkuat penjelasan tersebut oleh guru. Baru dilanjutkan dengan menjelaskan contoh yang ada dilingkungan sekitar siswa. Dalam memberikan penekanan pada bagian yang penting dilakukan penguatan dengan mengulangi kalimat dua kali. 


\section{3). Keterampilan bertanya}

Guru memberikan pertanyaan kepada siswa terkait materi yang diajarkan dengan menggunakan Bahasa yang jelas dan dimengerti oleh siswa. Kemudian memberikan pertanyaan kepada siswa, bagi yang bisa menjawab pertanyaan terlebih dahulu mengangkat tangan baru dilanjutkan menjawab. Guru juga mengulangi pertanyaan agar siswa mau menjawab, jika tidak ada siswa yang menjawab pertanyaan maka guru kembali dengan melakukan konsep yang berbeda kepada siswa, guru meminta siswa untuk membuat satu pertanyaan terhadap materi yang dipelajari sampai siswa mau bertanya.

\section{4). Keterampilan mengadakan variasi}

Dalam mengajar guru kelas V menggunakan berbagai variasi, baik variasi metode pembelajaran yang dilakukan dalam bentuk ceramah, tanya jawab, praktek dan diskusi kelompok. Selain itu, dalam media pembelajaran yang digunakan guru menggunakan buku pelajaran, infokus, praktek langsung dan disesuaikan dengan materi pelajaran [11].

\section{5). Keterampilan mengadakan variasi}

Guru memberikan penguatan secara verbal kepada siswa dengan mengatakan "bagus sekali yang disampaikan AR, beri tepuk tangan untuk AR". Selanjutnya dalam memerikan penguatan yang dilakukan dengan memberikan hadiah/tanda/komentar pada tugas tertulis itu tidak terlihat, tetapi berdasarkan wawancara dengan guru kelas $\mathrm{V}$ pemberian hadiah dilakukan pada akhir pembelajaran dari uang kas kelas.

\section{6). Keterampilan mengelola kelas}

Selama kegiatan pembelajaran yang dilakukan oleh guru kelas V suasana atau kondisi pada saat proses pembelajaran terkendali, tidak ribut, pembelajaran yang aktif, terjadinya stimulus atau tanya jawab pada saat proses pembelajaran, dalam pembelajaran juga dmemberikan motivasai kepada siswa, adanya pembelajaran yang menyenangkan dengan dilakukan permainan terlebih dahulu untuk mempokuskan perhatian siswa sehingga siswa bersemangat untuk mengikuti proses pembelajaran. Hasil penelitian ini sejalan dengan pendapat [12] pengelolaan kelas merupakan sesuatu yang dilakukan oleh guru untuk mencapai suasana pembelajaran yang efektif dan menyenangkan serta dapat memberikan motivasi kepada siswa sesuai dengan kemampuan yang dimiliki.

Berdasarkan hasil wawancara yang dilakukan guru kelas V, guru melibatkan siswa dalam pengaturan kondisi kelas dengan dilakukan kerja sama atau komitmen yang dibuat bersama, komitmen ini tidak bersifat permanen tetapi bisa berubah sesuai dengan kondisi atau keadaan yang terjadi. Dalam hal ini kepala sekolah juga mendukung untuk terjadinya proses pembelajaran yang optimal dengan disediakan infokus kepada setiap kelas, selain itu juga sarana dan prasarana di dalam kelas sangat mendukung terjadinya proses pembelajaran. Hasil penelitian ini sejalan dengan pendapat [13] pembelajaran adalah penyediaan kondisi belajar yang melibatkan terjadinya proses pembelajaran kepada siswa.

\section{7). Keterampilan mengajar dalam kelompok kecil dan perorangan}

Dalam mengajar kelompok kecil atau perorangan dilakukan dengan membagi siswa kedalam beberapa kelompok berdasarkan tempat duduk siswa yang diatur duduk berkelompok sebelum proses kegiatan pembelajaran dilakukan. Tempat duduk siswa diatur dan dibentuk secara Heterogen sehingga akan seimbang dalam pembelajaran. Dalam pemberian tugas kelompok guru menghampiri setiap anggota kelompok untuk memberikan penjelasan dan mempokuskan terhadap materi yang dibahas.

\section{8). Keterampilan memimpin diskusi dalam kelompok kecil}

Dalam memimpin diskusi dalam kelompok kecil guru memfokuskan perhatian siswa terhadap materi yang didiskusikan, agar tidak terjadi penyimpangan pada saat mengerjakan tugas kelompok dan sesuai dengan tujuan pembelajaran. Guru memberikan penguatan setelah setiap kelompok tampil di depan kelas menampilkan hasil diskusinya dan setelah semua kelompok tampil guru menutup diskusi sekaligus memberikan kesimpulan terhadap yang telah didiskusikan.

Kegiatan pembelajaran yang dilakukan oleh guru kelas $\mathrm{V}$ adalah pembelajaran yang menggunakan kurikulum 2013. Pada Kurikulum 2013 pembelajaran dilakukan dengan menggunakan pembelajaran tematik terpadu [14]. Pembelajaran yang berdasarkan tema, tema dibuat sesuai dengan karakteristik dan lingkungan tempat tinggal siswa, tema disini berperan sebagai pemersatu mata pelajaran lain, sehingga pembelajaran tidak terpisah tetapi padu dalam sebuah tema. Guru mengajar berdasarkan tema yang ada dibuku bukan berdasarkan mata pelajaran dan tidak terpisah. Hasil penelitian ini sejalan dengan pendapat Widyaningrum (2012) menerangkan pada pembelajaran tematik terpadu pembelajaran dilakukan dengan menggunakan tema untuk mempersatu mata pelajaran sehingga pembelajaran yang dilakukan memiliki kebermaknaan bagi siswa[15]. 


\section{KESIMPULAN}

Berdasarkan hasil penelitian yang dilakukan tentang pengelolaan kelas pada pembelajaran tematik terpadu oleh guru kelas V Sekolah Dasar Negeri 122/IX Petaling dapat disimpulkan bahwa guru telah melaksanakan pengelolaan kelas pada pembelajaran tematik terpadu dikelas dengan baik, itu terlihat dengan berdasarkan keterlaksanaan indikator yang digunakan pada saat peneliti melakukan pengamatan secara langsung atau observasi dan didukung dengan hasil wawancara dan dokumentasi. Guru melaksanakan pembelajaran sesuai dengan indikator yang dijadikan pedoman dalam penelitian, dimana guru telah melaksanakan tugasnya mulai dari membuka dan menutup pelajaran, menjelaskan pelajaran, bertanya, mengadakan variasi, memberikan penguatan, mengelola kelas, mengajar dalam kelompok kecil dan perorangan dan memimpin diskusi dalam kelompok kecil.

Dalam melakukan pengelolaan kelas pada pembelajaran tematik terpadu di kelas $\mathrm{V}$ terdapat hambatan seperti terkendala pada buku pembelajaran, tetapi guru bisa mengatasi hal tersebut dan siswa tetap belajar dengan menggunakan buku dari sumber lain yang tidak menyelimpang dari kurikulum yang sedang digunakan.

\section{UCAPAN TERIMA KASIH}

Terimakaish kepada seluruh responden yang telah bersedia, sehingga penelitian ini dapat saya selesaikan. Serta semua elemen yang telah ikut berpartisipasi, saya ucapkan terimakasih

\section{REFERENSI}

[1] Mamik, sutirjo dan. Penerapan Pembelajaran Tematik untuk Meningkatkan Hasil Belajar IPA Materi Pada Lingkungan Siswa Kelas I SDN 018 Letawa Kecamatan Sarjo Kabupaten Mamuju Utara. Jurnal Kreatif Tadulako, 3(2), 190- 204. 2013

[2] Majid. Strategi Pembelajaran. (Kuswandi, Ed.) (Cetakan Ke). Bandung: PT Remaja Rosdakarya Offiset. 2014

[3] A. Asrial, S. Syahrial, D. A. Kurniawan, R. Septiasari, "Hubungan Kompetensi Pedagogik Dengan Kompetensi IPA Mahasiswa Pendidikan Guru Sekolah Dasar,” Pedagogia: Jurnal Penididikan, vol. 8, no. 2, pp. 149-157, 2019

[4] S. Syahrial, A. Asrial, D. A. Kurniawan, P. Nugroho, R. Septiasari, R. A. Pratama, and R. Perdana, "Increased Behavior of Students' Attitudes to Cultural Values Using the Inquiry Learning Model Assisted Ethno constructivism," Journal of Educational Science and Technology (EST), vol. 5, no. 2, pp. 166-175, 2019

[5] A. Asrial, S. Syahrial, D. A. Kurniawan, and N. Amalina, "Analisis Hubungan Kompetensi Bahasa Indonesia Terhadap Kompetensi Pedagogik Mahasiswa Pendidikan Guru Sekolah Dasar," Premiere Educandum: Jurnal Pendidikan Dasar dan Pembelajaran, vol. 9, no. 1, pp. 1-8, 2019.

[6] A. Asrial, S. Syahrial, D. A. Kurniawan, M. Subandiyo, and N. Amalina, "Exploring Obstacles in Leanguage Learning Among Prospective Primay School Teacher," International Journal of Evaluation and Research in Education, vol. 8, no. 2, pp. 249-254, 2019

[7] D. A. Kurniawan, A. Astalini, D. Darmaji, R. Melsayanti, "Student's Attitude Towards Natural Science," International Journal of Evaluation and Research in Education (IJERE), vol. 8, no. 3, pp. 463-468, 2019

[8] Sugiono, "Metode Pendidikan" (kuantitatif, kualitatif, dan R\&D). Bandung : Alfabeta Cv, 2015

[9] Darmaji, D. A Kurniawan, Astalini, A. Lumbantoruan, and S. C. Samosir. "Mobile Learning In Higher Education For The Industrial Evolutioin 4.0: Perception and Response of Physics Practicum," International Journal of Interactive Mobile (IJIM), vol. 13, no. 9, pp. 4-20, 2019

[10] M. Maison, D. Darmaji, A. Astalini, D. A. Kurniawan, and P. Indrawati, "Science process skills and motivation," Humanities \& Social Sciences Reviews (HSSR), vol. 7, no. 5, pp. 48-56, 2019

[11] D. Darmaji, D. A. Kurniawan, A. Astalini, and N. R. Nasih, "Persepsi Mahasiswa pada Penuntun Praktikum Fisika Dasar II Berbasis Mobile Learning," Jurnal Pendidikan: Teori, Penelitian, dan Pengembangan, vol. 4, no. 4, pp. 516-523, 2019.

[12] Hilali, H. El. Pentingnya pengelolaan kelas dalam pembelajaran. Jurnal Edu-Bio, 3, 129-136. D. 2012

[13] Nurdiansyah, F. Inovasi Model Pembelajaran. (Nizamia Learning Centered, Ed.) (Cetakan Pe). Sidoarjo. 2013

[14] Darmaji, A. Astalini, D. A. Kurniawan, and R. Perdana, "A study relationship attitude toward physics, motivation, and character discipline students senior high school, in Indonesia," International Journal of Learning and Teaching, vol. 11, no. 3, pp. 99-109, 2019.

[15] Widyaningrum, R. Model Pembelajaran Tematik di MI/SD. Cendekia, 10(1), 108-120. 2012. 